\title{
REVIEW
}

\section{What is the optimal management option for occupational asthma?}

\author{
Olivier Vandenplas*, Holger Dressel ${ }^{\#}$, Dennis Nowak and Jacques Jamart ${ }^{+}$ \\ on behalf of the ERS Task Force on the Management of Work-related Asthma ${ }^{\S}$
}

ABSTRACT: The optimal management of occupational asthma remains uncertain in clinical practice. The aim of this review was to analyse the published information pertaining to the management of occupational asthma in order to produce evidence-based statements and recommendations.

A systematic literature search was conducted up to March 2010 to identify original studies addressing the following different treatment options: 1) persistence of exposure; 2) pharmacological treatment; 3) complete avoidance of exposure; 4) reduction of exposure; and 5) the use of personal protective equipment.

After full text evaluation of $\mathbf{8 3}$ potentially relevant articles, $\mathbf{5 2}$ studies were retained for analysis. The conclusions from this systematic review are limited by the methodological weaknesses of most published studies. Critical analysis of available evidence indicates that: 1) persistent exposure to the causal agent is more likely to result in asthma worsening than complete avoidance; 2) there is insufficient evidence to determine whether pharmacological treatment can alter the course of asthma in subjects who remain exposed; 3) avoidance of exposure leads to recovery of asthma in less than one-third of affected workers; 4) reduction of exposure seems to be less beneficial than complete avoidance of exposure; and 5) personal respiratory equipment does not provide complete protection.

KEYWORDS: Asthma, occupational diseases, outcome assessment, prognosis, respiratory protective devices

or many years, the recommended therapeutic approach for immunologically mediated occupational asthma (i.e. occupational asthma with a latency period) has been the cessation of exposure to the sensitising agent through either the movement of the worker to an unexposed job or the elimination of the sensitising agent from the workplace [1-3]. However, there has been a growing recognition that complete avoidance of exposure is often associated with not only adverse social and financial consequences for affected workers, but also with a substantial economic impact for society as a whole [4-6]. This is likely to account for the consistent finding that about one-third of workers with occupational asthma remain exposed to the causal agent [4]. In addition, the efficacy of complete exposure avoidance on asthma outcome seems quite limited $[7,8]$. However, continued but reduced exposure to the causal agent may lead to an improvement in asthma and has been considered as an alternative in order to minimise the detrimental consequences on employment, income and quality of life [1-2,9]. The outcome of occupational asthma after treatment interventions has been examined in systematic reviews of the literature published up to 2004 $[1,7,8]$, but there remains uncertainty as to whether exposure cessation is the optimal approach to manage occupational asthma. The purpose of this systematic review was to synthesise and critically analyse the scientific literature pertaining to the management options of occupational asthma in order to issue statements and recommendations aimed at the medical community, workers, employers and policy-makers.

\section{METHODS}

The statements and recommendations formulated in this article are based on a systematic evaluation of the international literature according to the methods extensively described by BAUR et al. [10] and in [11] (table 1).
AFFILIATIONS

*Dept of Chest Medicine, and ${ }^{+}$Scientific Support Unit, MontGodinne Hospital, Université Catholique De Louvain, Yvoir, Belgium.

\#Städt. Klinikum München GmbG, Klinikum Neuperlach Zentrum für Akutgeriatrie und Frührehabilitation, and "Institute und Poliklinik für Arbeits- und Umweltmedizin der Ludwig-Maximilians-Universität, Klinikum der Universität München, Munich, Germany.

${ }^{\S}$ For a full list of the members of the Task Force, see the Acknowledgements.

CORRESPONDENCE

0 . Vandenplas

Dept of Chest Medicine

Mont-Godinne Hospital

Université Catholique de Louvain

Yvoir

Belgium

E-mail: olivier.vandenplas@

uclouvain.be

Received:

June 072011

Accepted after revision:

July 052011

\section{PROVENANCE}

Submitted article, peer reviewed. 


TABLE 1 Ancillary questions pertaining to the management
of occupational asthma
What are the consequences of persistent exposure to the causal agent?
Is it possible to improve symptoms and lung function by pharmacological
treatment in affected workers with persistent exposure?
What is the effectiveness of complete avoidance of exposure?
What is the effectiveness of reducing exposure through engineering control or
relocation of affected workers?
What is the effectiveness of reducing exposure through personal protective
equipment?

Modified from [10], with permission from the publisher.

Search results, as well as a list of considered articles, were included in evidence tables and presented in the online supplementary material of [10].

Considering the substantial heterogeneity of reported clinical and functional outcomes in follow-up studies of occupational asthma [7, 8], any quantitative analysis of the effects of interventions was deliberately restricted to simple outcomes, "symptom recovery" and "nonspecific bronchial hyperresponsiveness (NSBHR) recovery", which were evaluated according to the criteria used in each study, as proposed by RACHIOTIS et al. [8]. The pooled prevalence estimates of these outcomes were computed using a random-effect model through MetaAnalyst Beta 3.13 software [12].

\section{RESULTS}

462 titles were identified in the systematic literature search. After full evaluation, we selected 50 that were relevant for the questions.

The results of the bibliographic search for each of the predefined ancillary questions as well as the reasons for excluding some studies, and the characteristics, main findings and quality assessment of the selected publications are available in the online supplementary material of [10].

\section{What are the consequences of persistent exposure to the causal agent?}

The bibliographic search identified nine studies that compared the effects of persistence of exposure to sensitising agents with those resulting from complete avoidance in the same populations of workers affected with occupational asthma (table 2) [13-21]. Asthma symptoms persisted in almost all (93.0\%, 95\% CI 86.3-96.6\%) patients who remained exposed, while $33.7 \%$ (95\% CI $23.6-45.6 \%)$ of those who avoided exposure recovered from their asthma. The two studies that provided information on worsening of asthma reported that the condition deteriorated in 10 (59\%) out of 17 subjects who remained exposed, but in none of those who avoided exposure [18, 20]. The few studies that compared the outcome in terms of functional parameters reported that persistence of exposure was associated with a decrease in forced expiratory volume in $1 \mathrm{~s}$ (FEV1) $[13,16,20]$ and an increase in NSBHR [13, 20] compared with cessation of exposure; although the differences were significant in only one study [20]. Two retrospective cohort studies specifically investigated changes in FEV1 according to cessation or persistence of exposure to the sensitising agent. LIN et al. [22] found that patients with occupational asthma caused by red cedar dust who continued to be exposed had a more rapid decline in FEV1 $\left(-26 \mathrm{~mL} \cdot \mathrm{yr}^{-1}\right)$ than a control population of cedar sawmill workers. ANEES et al. [23] evaluated the changes in FEV1 before and after removal from exposure in 44 out of 156 consecutive subjects with occupational asthma (87\% due to low-molecular-weight agents) who underwent measurements within $1 \mathrm{yr}$ before and after removal and could serve as their own control. The mean \pm SE rate of decline in FEV1 was significantly greater before $(-119.8 \pm$ $\left.26.3 \mathrm{~mL} \cdot \mathrm{yr}^{-1}\right)$ than after cessation of exposure $\left(+9.8 \pm 31 \mathrm{~mL} \cdot \mathrm{yr}^{-1}\right)$, with a mean difference of $-129.6 \mathrm{~mL} \cdot \mathrm{yr}^{-1}$ (95\% CI $-217--42$ $\left.\mathrm{mL} \cdot \mathrm{yr}^{-1}\right)$. Only one prospective study compared asthma severity, disease-related costs and work-derived income after cessation or persistence of exposure to various agents causing occupational asthma. Noticeably, the investigators did not clearly distinguish the persistence of exposure to the same conditions at work from a reduction of exposure to the causal

TABLE 2 Comparison between persistence and avoidance of causal exposure

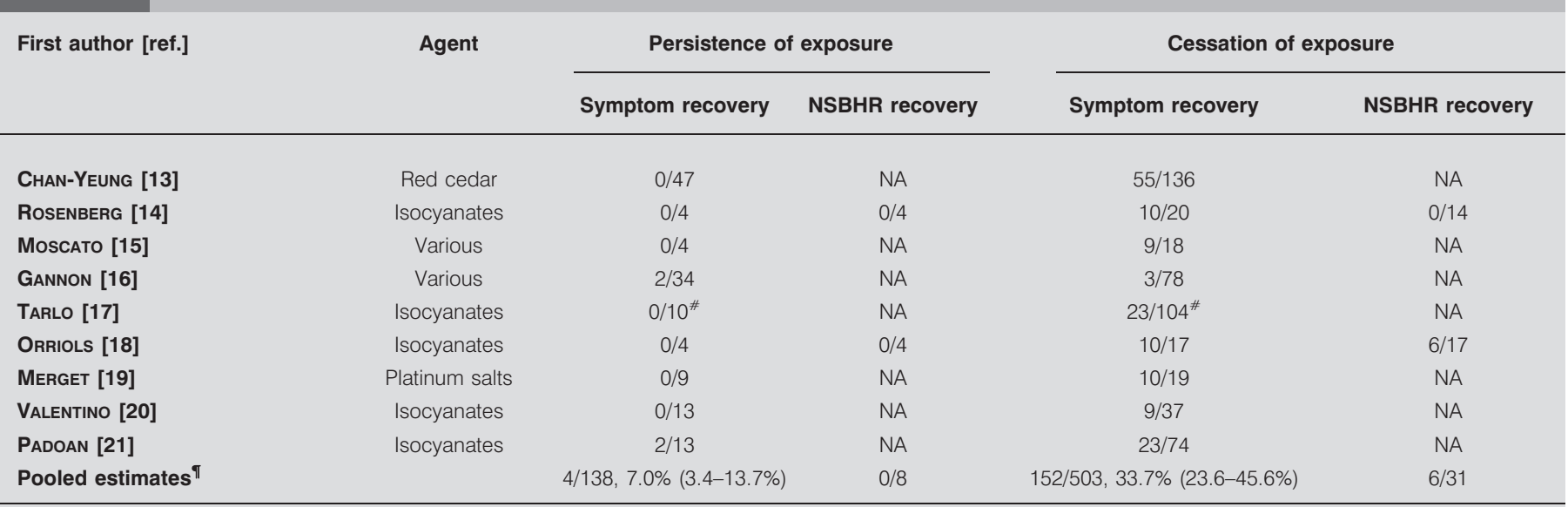

Individual study data are presented as $\mathrm{n} / \mathrm{N}$. Pooled estimates are presented as $\mathrm{n} / \mathrm{N}$ with or without $\%(95 \% \mathrm{Cl})$. NA: not available; NSBHR: nonspecific bronchial hyperresponsiveness. ": "Global assessment of asthma"; ": pooled estimates based on a random-effect model. 
TABLE 3 Avoidance of exposure: characteristics and results of studies published between 2004 and 2010

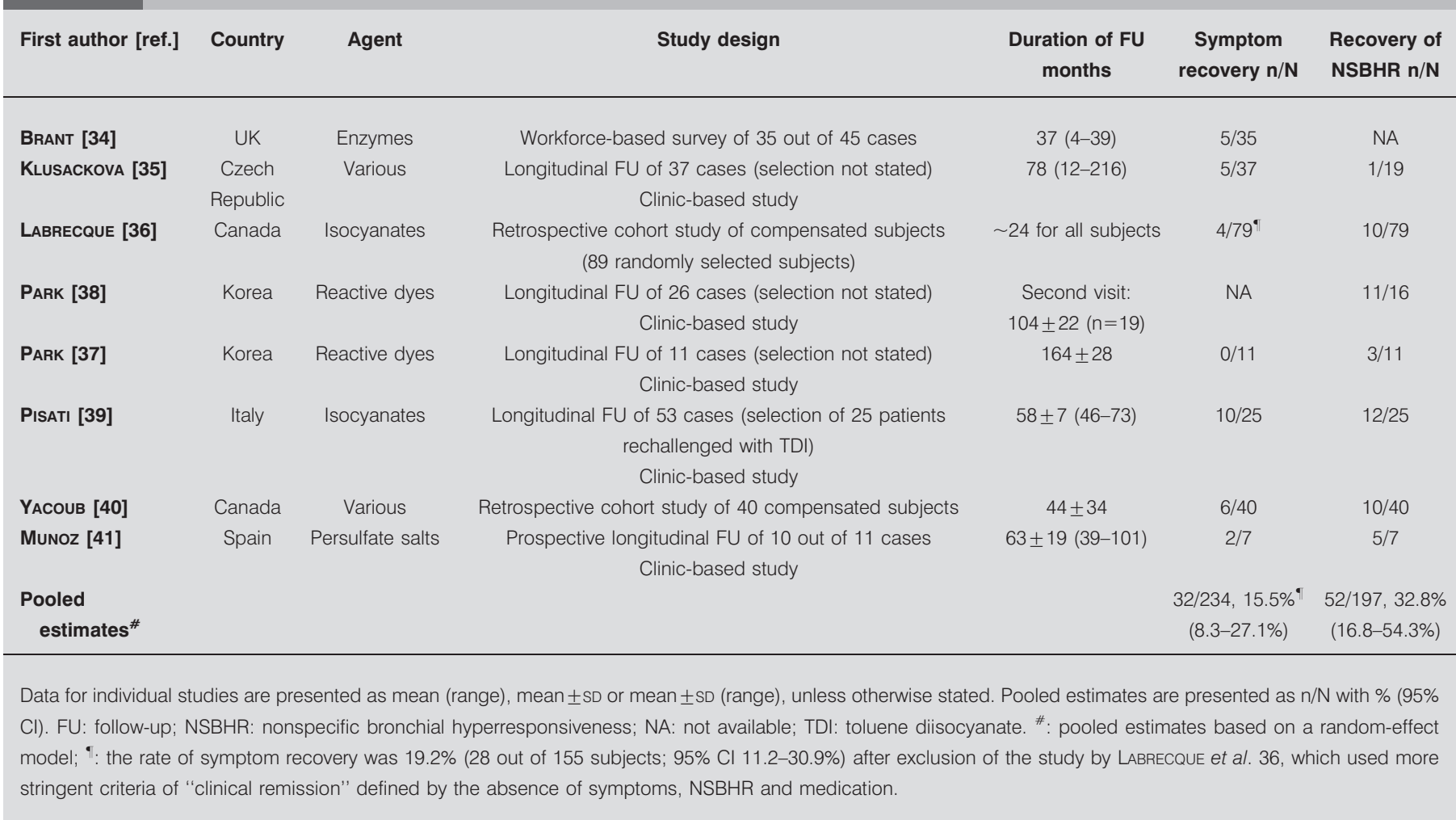

agent, since $43 \%$ of the subjects with persistent exposure actually had intermittent or lower exposure [24]. When compared with persistence of exposure to causal agents, complete avoidance resulted in a significant decrease in asthma severity and healthcare expenses, but also in work-derived income [24].

\section{Is it possible to improve symptoms and lung function using pharmacological treatments in affected workers with persistent exposure?}

The effectiveness of anti-asthma medications in patients with persistent exposure has been evaluated in one uncontrolled intervention study [27] and one retrospective cohort study [23]. MARABINI et al. [25] reported that there was no significant deterioration in any of the asthma outcomes compared with baseline values in 10 subjects with occupational asthma due to various agents who were treated with inhaled corticosteroids and long-acting $\beta_{2}$-agonists over a 3 -yr period. In contrast, ANEES et al. [23] reported that the decline in FEV1 before removal from exposure to agents causing occupational asthma was not affected by the use of inhaled corticosteroids. Several case reports and uncontrolled case series have reported a beneficial effect of specific immunotherapy with some high-molecular-weight allergens (i.e. sea squirt allergens, natural rubber latex and laboratory animals) [26], but only a few well-conducted studies have been published. ARMENTIA and co-workers [27, 28] conducted a placebo-controlled, double-blind trial of subcutaneous immunotherapy with a flour extract in 30 workers with occupational asthma. The treated patients showed a significant decrease in symptoms, NSBHR to methacholine, skin sensitivity and specific immunoglobulin (Ig)E to wheat flour without any adverse reactions. Two randomised, double-blind, placebo-controlled trials evaluated the effectiveness of specific subcutaneous immunotherapy in healthcare workers with latex allergy [29, 30]. These studies documented an improvement in rhinoconunctivitis symptoms and a reduction in skin reactivity to latex, but there was no clear improvement in asthma outcomes. In addition, latex immunotherapy resulted in a high rate of systemic adverse reactions. There has been some suggestion that sublingual immunotherapy may be effective in latex allergy [31].

Recent case reports have provided some suggestion that treatment with omalizumab could substantially improve asthma control in subjects with flour-induced occupational asthma who remain exposed to the causal work environment [32,33], although further investigations are required.

\section{What is the effectiveness of complete avoidance of exposure?}

Two systematic reviews examined the outcome of workers with occupational asthma after cessation of exposure to the causal agent in studies published up to $2004[7,8]$. The bibliographic search identified eight follow-up studies of workers removed from exposure that met the inclusion criteria used by RACHIOTIS et al. [8] and were published after March 2004 (table 3) [34-41]. These studies yielded estimated rates of symptomatic recovery $(15.5 \%$, 95\% CI $8.3-27.1 \%)$ ) and persistence of NSBHR $(67.2 \%, 95 \%$ CI $45.7-83.2 \%)$ that were in line with those reported in the systematic review by RACHIOTIS et al. [8]. Two retrospective cohort studies explored the long-term changes in functional indices after cessation of exposure: MALO et al. [42] showed that the improvement in 
TABLE 4 Assessment of respiratory protective equipment (RPE)

\begin{tabular}{|c|c|c|c|c|}
\hline First author [ref.] & Design & Agent & Type of RPE & Effects of RPE \\
\hline MulLeR-Wening [54] & $\begin{array}{l}\text { Laboratory challenge } \\
\text { Non-RCT study } \\
n=26\end{array}$ & $\begin{array}{l}\text { Organic farm } \\
\text { allergens }\end{array}$ & $\begin{array}{l}\text { RPE with P2 filter: "Dustmaster" } \\
(n=21) \text {, "Airstream helmet" }(n=4) \text {, } \\
\text { "Airlite" }(n=1)\end{array}$ & $\begin{array}{l}\text { Suppression of symptoms in } 11 \text { out of } 26 \text {, } \\
\text { reduction in } 15 \text { out of } 26 \text {, but } 4 \text { required } \\
\text { inhaled bronchodilator }\end{array}$ \\
\hline LAOPRASERT [55] & $\begin{array}{l}\text { Exposure: } 1 \mathrm{~h} \text {, not quantified } \\
\text { Laboratory challenge } \\
\text { RCT study with placebo } \\
\qquad \mathrm{n}=9\end{array}$ & Latex & Laminar flow HEPA-filtered helmet & $\begin{array}{l}\text { Reduction of the increase in airway resistance } \\
\text { Reduction of symptom score } \\
\text { Reduction of the decline in FEV } 1\end{array}$ \\
\hline SLOVAK [56] & $\begin{array}{l}\text { Exposure: } 1 \mathrm{~h} \text {, quantified } \\
\text { Workplace exposure } \\
\text { Non-controlled study }\end{array}$ & $\begin{array}{l}\text { Laboratory } \\
\text { animals }\end{array}$ & $\begin{array}{c}\text { Powered helmet respirator } \\
\text { with AS-23-3 filter }\end{array}$ & $\begin{array}{c}\text { Worsening of symptoms in } 2 \text { out of } 8 \\
\text { (score not available) }\end{array}$ \\
\hline & $\begin{array}{l}n=8 \\
\text { Exposure: } 6 \text { weeks, not-quantified }\end{array}$ & & & Peak flow variation at work in 2 out of 8 \\
\hline KONGERUD [57] & $\begin{array}{c}\text { Workplace exposure } \\
\text { RCT study } \\
\mathrm{n}=19 \text { workers with nonsevere } \\
\text { disease } \\
\text { Exposure: } 2 \text { weeks, not quantified }\end{array}$ & $\begin{array}{l}\text { Aluminium pot } \\
\text { room }\end{array}$ & AH60 Airsteam helmet & $\begin{array}{l}\text { Reduction of symptom score in } 10 \text { out of } 17 \\
\text { subjects (nonsignificant) } \\
\text { Improvement in the mean peak flow values }\end{array}$ \\
\hline TAIVAINEN [58] & $\begin{array}{l}\text { Workplace exposure } \\
\text { Non-RCT study } \\
n=24 \\
\text { Exposure: } 10 \text { months, } \\
\text { not quantified }\end{array}$ & Farming & $\begin{array}{l}\text { Powered dust respirator helmet } \\
\text { with P2 filter }\end{array}$ & $\begin{array}{l}\text { No effect on respiratory symptoms with the exception } \\
\text { of sputum, rhinitis symptoms, corticosteroid } \\
\text { treatment, and number of sick leaves } \\
\text { Increase in morning peak flow and reduced } \\
\text { daily peak flow variability }\end{array}$ \\
\hline
\end{tabular}

RCT: randomised controlled trial; HEPA: high-efficiency particulate arrest; FEV1: forced expiratory volume in $1 \mathrm{~s}$.

NSBHR can continue for years after cessation of exposure, but the rate of improvement is steeper during the first 2.5 yrs. ANEES et al. [23] found that the decline in FEV1 after removal from exposure is similar to that observed in healthy adults [23]. Recent studies using induced sputum analysis have documented that failure to improve NSBHR after cessation of exposure was associated with persistent airway inflammation [43, 44], but inflammation [40] and airway remodelling [45] may be present in subjects who have recovered from symptoms and NSBHR.

Two randomised controlled trials assessed the effects of systematic treatment with inhaled corticosteroids in addition to cessation of exposure [46, 47]. MAESTRELLI et al [46]. found that treatment with beclomethasone dipropionate (1 mg twice daily for 5 months) was associated with reduced NSBHR. MALO et al. [47]. showed that beclomethasone dipropionate (1 mg daily) was associated with a significant, though minimal, improvement in symptoms, peak expiratory flow and quality of life.

\section{What is the effectiveness of reducing exposure through engineering control or relocation of affected workers?}

The bibliographic search identified 10 studies that compared the target asthma outcomes (i.e. improvement, recovery, and worsening of asthma symptoms and NSBHR) in subjects who reduced exposure to the causal agent with those who completely avoided exposure [13-15, 19, 41, 48-52]. The detailed methodology and results of the meta-analysis of these studies have been published elsewhere [53]. The studies evaluated 186 patients who had reduced exposure and 292 who had avoided exposure to the causal agent. The most commonly identified causal agents, in seven out of 10 publications, were lowmolecular-weight agents, including isocyanates [14, 49, 50], colophony [48], red cedar dust [13], platinum salts [19] and persulfate salts [41]. Two studies involved a single highmolecular-weight agent, natural rubber latex [51, 52], and one study evaluated patients with occupational asthma caused by various agents, of which $90 \%$ were low molecular weight agents [15]. The changes in asthma symptoms and NSBHR after reduction or cessation of exposure were described in nine and five studies, respectively. The meta-analysis of pooled data showed that a reduction of exposure was associated with a lower likelihood of improvement (OR 0.16, 95\% CI 0.03-0.91) and recovery (OR $0.30,95 \%$ CI $0.11-0.84$ ) of asthma symptoms and a higher risk of worsening of the symptoms (OR 10.23, 95\% CI 2.97-35.28) and NSBHR (OR 5.65, 95\% CI 1.11-28.82) compared with complete avoidance of exposure.

Two publications reported on the socioeconomic outcomes of workers with occupational asthma caused by colophony [48] and natural rubber latex gloves [51].

These studies revealed that the rate of unemployment was significantly higher among those who avoided exposure compared with those who reduced exposure. Among workers with latex-induced occupational asthma [51], a "major" loss of income was more frequently reported by subjects who ceased exposure to latex than by those who remained exposed to reduced levels of latex. 


\section{What is the effectiveness of reducing exposure through personal protective equipment?}

We identified five studies that assessed the short-term effectiveness of various types of respiratory protective equipment (RPE) in patients with occupational asthma using inhalation challenges in the laboratory with organic farm allergens [54] and latex [55] or through workplace exposure to laboratory animals [56] or aluminium pot room atmosphere [57], and farming activities [58]. The characteristics and findings of these studies are summarised in table 4 . Overall, these studies showed that the use of RPE led to a significant reduction in respiratory symptoms and changes in functional parameters during short-term exposures, but failed to provide complete protection. Notably, one study documented that there was no protective effect in workers with more severe asthma or in those who used RPE irregularly [58].

One retrospective study of workers with occupational asthma induced by red cedar dust who remained exposed to the causal agent provided indirect evidence supporting a beneficial longterm effect of some types of RPE [59]. In this study, the proportion of subjects who used a twin-cartridge respirator was significantly higher among the group with stable asthma than among the group with a deterioration of asthma.

\section{DISCUSSION}

Determining the most effective treatment for occupational asthma would necessitate having precise information on the effect of different management options on clinical, physiological, and socioeconomic outcomes. However, the evidence that can be derived from current data is largely limited by methodological weaknesses. Most published data are observational, nonrandomised follow-up studies. The rationale for the intervention decision (i.e. persistence, reduction, or cessation of exposure) is most often unknown, leading to a high potential for selection biases. In addition, asthma outcomes are measured and expressed in a highly heterogeneous manner. Finally, almost none of the studies relied on quantitative exposure assessments of environmental interventions, such as reduction of exposure. Nevertheless, the information retrieved from the systematic analysis of available data has led us to issue the following consensus statements; level of evidence was graded using the modified 1995 Royal College of General Practitioners (RCGP) three-star system [60] (see online supplementary material of [10]).

\section{Persistence of exposure to the agent causing occupational asthma is more likely to be associated with the persistence of asthma and NSBHR, and an accelerated decline in FEV1, compared with complete avoidance of exposure ${ }^{* *}$ moderate evidence)}

The systematic review conducted by the Agency for Healthcare Research and Quality (AHRQ) [7] concluded that workers with occupational asthma who remain exposed to the causal agent continue to experience stable or worsened asthma symptoms and tend to show a decrease in FEV1 over time, as well as an increase in NSBHR. The consequences of persistent exposure were not specifically examined in the clinical practice guidelines issued by the British Occupational Health Research Foundation (BOHRF) [1] and the American College of Chest Physicians (ACCP) [2].
2. There is currently insufficient evidence that treatment with inhaled corticosteroids and long-acting $\beta_{2}$-agonists is able to prevent the long-term deterioration of asthma in subjects who remain exposed to the agent causing occupational asthma (* limited evidence).

\section{There is a lack of evidence-based information on the} effectiveness and adverse effects of specific immunotherapy with high molecular weight occupational allergens (** moderate evidence)

The effectiveness of anti-asthma medications in patients who remain exposed to the causal agent was not specifically addressed in previously published guidelines [1,2] or in the AHRQ systematic review [7]. Despite the dearth of data on the effectiveness of immunotherapy in occupational asthma, the ACCP guidelines concluded that immunotherapy may be an effective management option in individuals with sensitiserinduced occupational asthma due to selected high-molecularweight agents when a commercial extract is available and the causative agent cannot be completely avoided for economic, professional or other reasons [2]. As outlined by the ACCP guidelines, further investigations are required to evaluate the effectiveness of treatment with omalizumab in subjects who choose to continue exposure [2]. These therapeutic approaches were not addressed in the BOHRF guidelines [1].

4. Occupational asthma is associated with a substantial long-term morbidity, since complete avoidance of exposure to the causal agent results in symptom recovery and resolution of NSBHR in less than one-third of affected workers ( ${ }^{* *}$ strong evidence)

5. There is insufficient evidence to support systematic treatment with high-dose inhaled corticosteroids after cessation of exposure (** moderate evidence)

The AHRQ systematic review [7] stated that most of the available studies documented an improvement in asthma symptoms and NSBHR, and an increase in mean FEV1, although only a few reported complete resolution of symptoms in the majority of the subjects. The analysis of studies published since 2004 confirms the low rates of recovery after cessation of exposure that were found by RACHIOTIS et al. [8] in studies published before 2004: 32\% (95\% CI 26-38\%) for symptomatic recovery and 73\% (95\% CI 66-79\%) for persistence of NSBHR.

\section{Reduction of exposure to the causal agent can lead to} improvement or resolution of symptoms and NSBHR, although the limited available evidence indicates that this approach is less beneficial than cessation of exposure (** moderate evidence) The AHRQ systematic review [7] analysed the outcome of symptoms [14, 19, 48, 51, 61-65], asthma medications [14, 48, 51, 61, 66], FEV1, [14, 48, 51] and NSBHR [14, 48, 51] after the reduction of exposure in studies published up to 2004. The authors concluded that these data documented some improvement in asthma symptoms; no clear pattern of changes in medication use; an improvement in FEV1 over time in less than half of the studies; and provided insufficient data (improvement in one of three studies) to draw conclusions about the changes in NSBHR. The guidelines of the BOHRF and ACCP stated that reduction of exposure "is not always effective" [1] and that "there is little evidence for using this approach" [2]. 


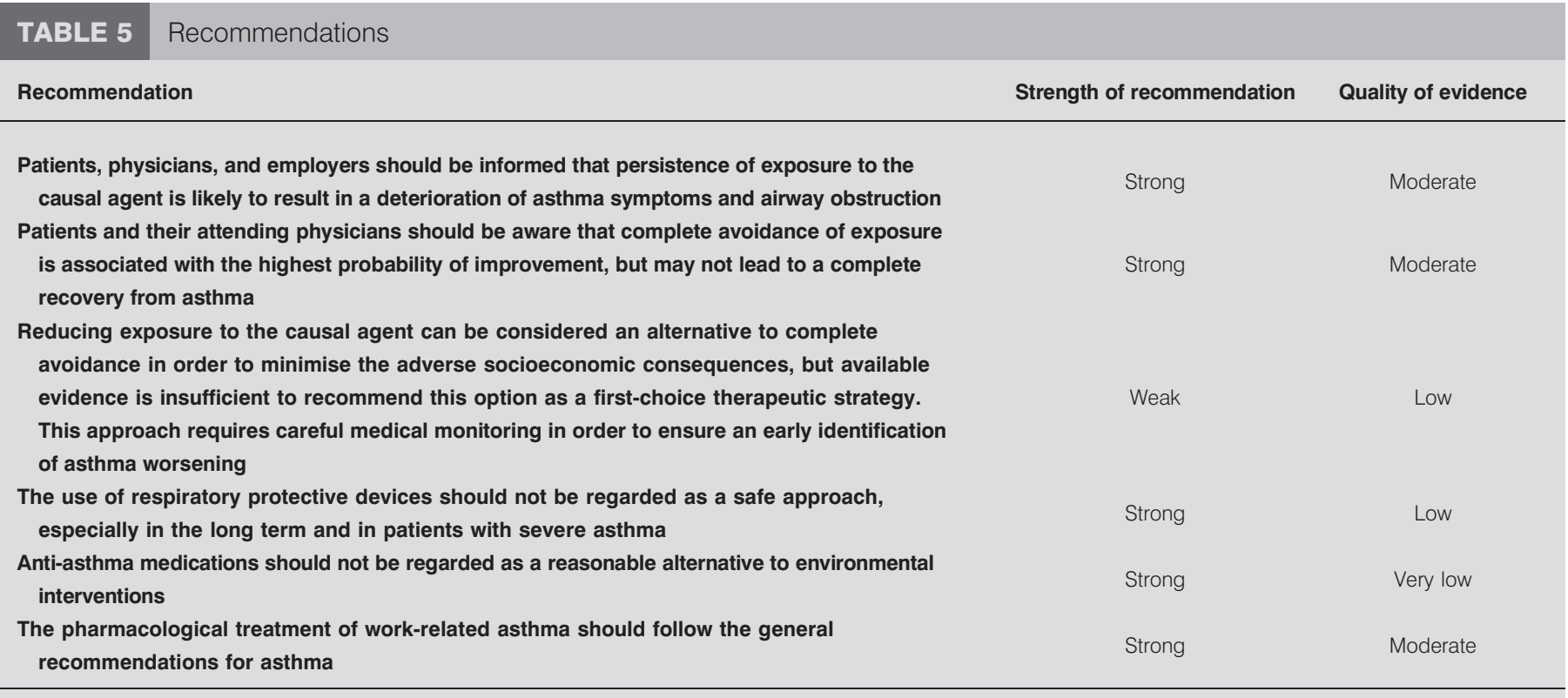

The strength of the recommendations and the quality of underlying evidence were graded using the Grading of Recommendations Assessment, Development and Evaluation approach [67]

\section{Respiratory personal equipment can result in an improvement-} but not a complete suppression - of respiratory symptoms and airway obstruction in the short term (** moderate evidence)

The conclusions of this systematic review about the effectiveness of RPE are in agreement with those of the AHRQ review [7] and the BOHRF guidelines [1]. In addition, none of these studies provided information on practical issues (e.g. compliance) that could result from the long-term use of RPE. RPE was not specifically addressed in the ACCP guidelines [2].

Based on the limited evidence provided by this systematic review, some recommendations can be made regarding the management of occupational asthma. These recommendations, along with their strength and the quality of available evidence, are presented in table 5. Large-scale prospective studies comparing the effectiveness and the socioeconomic impact of different treatment options are required in order to provide physicians, affected workers, employers and policy-makers with stronger evidence-based recommendations for the management of occupational asthma. Such studies should: investigate nonselected populations of workers with occupational asthma due to various agents; use the standard outcomes that have been validated for asthma in general; and incorporate quantitative exposure assessments.

\section{Future research}

There is a need for large-scale, standardised studies on the prognosis of occupational asthma and its determinants after environmental interventions in order to provide evidencebased recommendations to affected workers, employers, and policy-makers. Prospective studies of the prognosis of occupational asthma should use the outcomes that have been validated for asthma in general. Studies aimed at assessing the effects of reduced exposure to agents causing occupational asthma should include quantitative exposure estimates.
There is a need for prospective evaluation of the effectiveness of specific immunotherapy with validated extracts of highmolecular-weight agents and anti-IgE therapy as therapeutic alternatives when complete avoidance is not possible in IgEmediated occupational asthma caused by agents such as flour, laboratory animals and enzymes. Investigation of the effectiveness of specific immunotherapy to alter the natural history of the disease from rhinitis to asthma is also warranted.

\section{SUPPORT STATEMENT}

The work of the Task Force on the Management of Work-related Asthma was funded by the European Respiratory Society.

\section{STATEMENT OF INTEREST}

None declared.

\section{ACKNOWLEDGEMENTS}

The Task Force members are as follows: X. Baur (Chair; Institute for Occupational and Maritime Medicine, University Medical Centre Hamburg-Eppendorf, Hamburg, Germany); T. Sigsgaard (Co-Chair; Århus University, Institute of Environmental and Occupational Medicine, School of Public Health, Århus C, Denmark); T. Aasen (Haukeland University Hospital, Bergen, Norway); P.S. Burge (Heart of England NHS Foundation Trust, Dept of Respiratory Medicine, Birmingham, UK); H. Dressel (Städt. Klinikum München GmbH, Klinikum Neuperlach Zentrum für Akutgeriatrie und Frührehabilitation, München, Germany); D. Heederik (Environmental Epidemiology Division, Institute for Risk Assessment Sciences, University of Utrecht, Utrecht, the Netherlands); P.K. Henneberger (National Institute for Occupational Safety and Health, Centers for Disease Control and Prevention, Morgantown, WV, USA); P. Maestrelli (Dept of Environmental Medicine and Public Health, University of Padua, Padua, Italy); C.A. Redlich (Yale Occupational/Environmental, New Haven, CT, USA); J. Rooyackers (Netherlands Expertise Centre for Occupational Respiratory Disorders - NECORD IRAS NKAL, Utrecht, the Netherlands); V. Schlünssen (Århus Universitet, Århus C, Denmark); O. Vandenplas (Dept of Chest Medicine, Mont-Godinne Hospital, 
Université Catholique de Louvain, Yvoir, Belgium); D. Wilken (Institute for Occupational and Maritime Medicine, University Medical Centre Hamburg-Eppendorf, Hamburg, Germany).

\section{REFERENCES}

1 Nicholson PJ, Cullinan P, Taylor AJ, et al. Evidence based guidelines for the prevention, identification, and management of occupational asthma. Occup Environ Med 2005; 62: 290-299.

2 Tarlo SM, Balmes J, Balkissoon R, et al. Diagnosis and management of work-related asthma: American College Of Chest Physicians Consensus Statement. Chest 2008; 134: 1S-41S.

3 Fishwick D, Barber CM, Bradshaw LM, et al. Standards of care for occupational asthma. Thorax 2008; 63: 240-250.

4 Vandenplas O, Toren K, Blanc PD. Health and socioeconomic impact of work-related asthma. Eur Respir J 2003; 22: 689-697.

5 Driscoll T, Nelson DI, Steenland K, et al. The global burden of nonmalignant respiratory disease due to occupational airborne exposures. Am J Ind Med 2005; 48: 432-445.

6 Boyd R, Cowie H, Hurley F, et al. The True Cost of Occupational Asthma in Great Britain. Sudbury, Health and Safety Executive, 2006; pp. 1-122.

7 Beach J, Rowe BH, Blitz S, et al. Diagnosis and Management of Work-related Asthma. Evidence Report/Technology Assessment Number 129. AHRQ Publication No 06-E003-2. Rockville, Agency for Healthcare Research and Quality, 2005. www.ahrq.gov/clinic/ epcsums/asthworksum.htm Date last updated: October 2005.

8 Rachiotis G, Savani R, Brant A, et al. Outcome of occupational asthma after cessation of exposure: a systematic review. Thorax 2007; 62: 147-152.

9 Cullinan P. Occupational asthma. Occup Environ Med 2008; 65: 151.

10 Baur X, Sigsgaard T, Aasen T, et al. Overview of the guidelines management of work-related asthma. Eur Respir J 2012; 39: 529-545.

11 Harbour R, Miller J. A new system for grading recommendations in evidence based guidelines. BMJ 2001; 323: 334-336.

12 Wallace BC, Schmid CH, Lau J, et al. Meta-Analyst: software for meta-analysis of binary, continuous and diagnostic data. BMC Med Res Methodol 2009; 9: 80.

13 Chan-Yeung M, MacLean L, Paggiaro PL. Follow-up study of 232 patients with occupational asthma caused by western red cedar (Thuja plicata). J Allergy Clin Immunol 1987; 79: 792-796.

14 Rosenberg N, Garnier R, Rousselin X, et al. Clinical and socioprofessional fate of isocyanate-induced asthma. Clin Allergy 1987; 17: 55-61.

15 Moscato G, Bertoletti R, Biscaldi G, et al. Occupational asthma: fate and management after the diagnosis. G Ital Med Lav 1993; 15: 27-31.

16 Gannon PF, Weir DC, Robertson AS, et al. Health, employment, and financial outcomes in workers with occupational asthma. $\mathrm{Br} J$ Ind Med 1993; 50: 491-496.

17 Tarlo SM, Banks D, Liss G, et al. Outcome determinants for isocyanate induced occupational asthma among compensation claimants. Occup Environ Med 1997; 54: 756-761.

18 Orriols R, Drobnic ME, Munoz X, et al. Asma ocupacional por isocianatos: estudio de 21 pacientes [Occupational asthma due to isocyanates: a study of 21 patients]. Med Clin (Barc) 1999; 113: 659-662.

19 Merget R, Schulte A, Gebler A, et al. Outcome of occupational asthma due to platinum salts after transferral to low-exposure areas. Int Arch Occup Environ Health 1999; 72: 33-39.

20 Valentino M, Rapisarda V. Evoluzione dell'asma da isocianati in rapporto alla cessazione dell'esposizione: studio longitudinale su 50 soggetti [Course of isocyanate-induced asthma in relation to exposure cessation: longitudinal study of 50 subjects]. G Ital Med Lav Ergon 2002; 24: 26-31.

21 Padoan M, Pozzato V, Simoni M, et al. Long-term follow-up of toluene diisocyanate-induced asthma. Eur Respir J 2003; 21: 637-640.
22 Lin FJ, Dimich-Ward H, Chan-Yeung M. Longitudinal decline in lung function in patients with occupational asthma due to western red cedar. Occup Environ Med 1996; 53: 753-756.

23 Anees W, Moore VC, Burge PS. FEV1 decline in occupational asthma. Thorax 2006; 61: 751-755.

24 Moscato G, Dellabianca A, Perfetti L, et al. Occupational asthma: a longitudinal study on the clinical and socioeconomic outcome after diagnosis. Chest 1999; 115: 249-256.

25 Marabini A, Siracusa A, Stopponi R, et al. Outcome of occupational asthma in patients with continuous exposure: a 3-year longitudinal study during pharmacologic treatment. Chest 2003; 124: 2372-2376.

26 Sastre J, Quirce S. Immunotherapy: an option in the management of occupational asthma? Curr Opin Allergy Clin Immunol 2006; 6: 96-100.

27 Armentia A, Martin-Santos JM, Quintero A, et al. Bakers' asthma: prevalence and evaluation of immunotherapy with a wheat flour extract. Ann Allergy 1990; 65: 265-272.

28 Armentia A, Arranz M, Martin JM, et al. Evaluation of immune complexes after immunotherapy with wheat flour in bakers' asthma. Ann Allergy 1992; 69: 441-444.

29 Leynadier F, Herman D, Vervloet D, et al. Specific immunotherapy with a standardized latex extract versus placebo in allergic healthcare workers. J Allergy Clin Immunol 2000; 106: 585-590.

30 Sastre J, Fernandez-Nieto M, Rico P, et al. Specific immunotherapy with a standardized latex extract in allergic workers: a doubleblind, placebo-controlled study. J Allergy Clin Immunol 2003; 111: 985-994.

31 Patriarca G, Nucera E, Pollastrini E, et al. Sublingual desensitization: a new approach to latex allergy problem. Anesth Analg 2002; 95: 956-960.

32 Perez Pimiento A, Bueso Fernandez A, Garcia Loria J, et al. Effect of omalizumab treatment in a baker with occupational asthma. J Investig Allergol Clin Immunol 2008; 18: 490-491.

33 Olivieri M, Biscardo CA, Turri S, et al. Omalizumab in persistent severe bakers' asthma. Allergy 2008; 63: 790-791.

34 Brant A, Zekveld C, Welch J, et al. The prognosis of occupational asthma due to detergent enzymes: clinical, immunological and employment outcomes. Clin Exp Allergy 2006; 36: 483-488.

35 Klusackova P, Pelclova D, Jindriska Levedova D, et al. Occupational asthma after withdrawal from the occupational allergen exposure. Ind Health 2006; 44: 629-638.

36 Labrecque M, Khemici E, Cartier A, et al. Impairment in workers with isocyanate-induced occupational asthma and removed from exposure in the province of Quebec between 1985 and 2002 J Occup Environ Med 2006; 48: 1093-1098.

37 Park HW, Kim DI, Sohn SW, et al. Outcomes in occupational asthma caused by reactive dye after long-term avoidance. Clin Exp Allergy 2007; 37: 225-230.

38 Park JW, Yang JY, Kim CW, et al. Avoidance therapy in reactive dye-induced occupational asthma: long-term follow-up. Ann Allergy Asthma Immunol 2006; 97: 551-556.

39 Pisati G, Baruffini A, Bernabeo F, et al. Rechallenging subjects with occupational asthma due to toluene diisocyanate (TDI), after longterm removal from exposure. Int Arch Occup Environ Health 2007; 80: 298-305.

40 Yacoub MR, Lavoie K, Lacoste G, et al. Assessment of impairment/disability due to occupational asthma through a multidimensional approach. Eur Respir J 2007; 29: 889-896.

41 Munoz X, Gomez-Olles S, Cruz MJ, et al. Evolucion de la hiperrespuesta bronquial en pacientes con asma ocupacional por exposicion a sales de persulfato [Course of bronchial hyperresponsiveness in patients with occupational asthma caused by exposure to persulfate salts]. Arch Bronconeumol 2008; 44: 140-145.

42 Malo JL, Ghezzo H. Recovery of methacholine responsiveness after end of exposure in occupational asthma. Am J Respir Crit Care Med 2004; 169: 1304-1307. 
43 Maghni K, Lemière $\mathrm{C}$, Ghezzo $\mathrm{H}$, et al. Airway inflammation after cessation of exposure to agents causing occupational asthma. Am J Respir Crit Care Med 2004; 169: 367-372.

44 Piirila PL, Meuronen A, Majuri ML, et al. Inflammation and functional outcome in diisocyanate-induced asthma after cessation of exposure. Allergy 2008; 63: 583-591.

45 Sumi Y, Foley S, Daigle S, et al. Structural changes and airway remodelling in occupational asthma at a mean interval of 14 years after cessation of exposure. Clin Exp Allergy 2007; 37: 1781-1787.

46 Maestrelli P, De Marzo N, Saetta M, et al. Effects of inhaled beclomethasone on airway responsiveness in occupational asthma. Placebo-controlled study of subjects sensitized to toluene diisocyanate. Am Rev Respir Dis 1993; 148: 407-412.

47 Malo JL, Cartier A, Côté J, et al. Influence of inhaled steroids on recovery from occupational asthma after cessation of exposure: an 18-month double-blind crossover study. Am J Respir Crit Care Med 1996; 153: 953-960.

48 Burge PS. Occupational asthma in electronics workers caused by colophony fumes: follow-up of affected workers. Thorax 1982; 37: 348-353.

49 Paggiaro PL, Vagaggini B, Dente FL, et al. Bronchial hyperresponsiveness and toluene diisocyanate. Long-term change in sensitized asthmatic subjects. Chest 1993; 103: 1123-1128.

50 Pisati G, Baruffini A, Zedda S. Toluene diisocyanate induced asthma: outcome according to persistence or cessation of exposure. Br J Ind Med 1993; 50: 60-64.

51 Vandenplas O, Jamart J, Delwiche JP, et al. Occupational asthma caused by natural rubber latex: outcome according to cessation or reduction of exposure. J Allergy Clin Immunol 2002; 109: 125-130.

52 Bernstein DI, Karnani R, Biagini RE, et al. Clinical and occupational outcomes in health care workers with natural rubber latex allergy. Ann Allergy Asthma Immunol 2003; 90: 209-213.

53 Vandenplas O, Dressel H, Wilken D, et al. Management of occupational asthma: cessation or reduction of exposure? Eur Respir J 2011; 38: 804-811.

54 Muller-Wening D, Neuhauss M. Protective effect of respiratory devices in farmers with occupational asthma. Eur Respir J 1998; 12: 569-572.

55 Laoprasert N, Swanson MC, Jones RT, et al. Inhalation challenge testing of latex-sensitive health care workers and the effectiveness of laminar flow HEPA-filtered helmets in reducing rhinoconjunctival and asthmatic reactions. J Allergy Clin Immunol 1998; 102: 9981004.

56 Slovak AJ, Orr RG, Teasdale EL. Efficacy of the helmet respirator in occupational asthma due to laboratory animal allergy (LAA). Am Ind Hyg Assoc J 1985; 46: 411-415.

57 Kongerud J, Rambjor O. The influence of the helmet respirator on peak flow rate in aluminum potroom. Am Ind Hyg Assoc J 1991; 52: 243-248.

58 Taivainen AI, Tukiainen HO, Terho EO, et al. Powered dust respirator helmets in the prevention of occupational asthma among farmers. Scand J Work Environ Health 1998; 24: 503-507.

59 Côté J, Kennedy S, Chan-Yeung M. Outcome of patients with cedar asthma with continuous exposure. Am Rev Respir Dis 1990; 141: 373-376.

60 Royal College of General Practitioners. The Development and Implementation of Clinical Guidelines: Report of the Clinical Guidelines Working Group. London, Royal College of General Practitioners, 1995.

61 Banks DE, Rando RJ, Barkman HW Jr. Persistence of toluene diisocyanate-induced asthma despite negligible workplace exposures. Chest 1990; 97: 121-125.

62 O'Donnell TV, Welford B, Coleman ED. Potroom asthma: New Zealand experience and follow-up. Am J Ind Med 1989; 15: 43-49.

63 Harries MG, Burge PS, Samson M, et al. Isocyanate asthma: respiratory symptoms due to 1,5-naphthylene di-isocyanate. Thorax 1979; 34: 762-766.

64 Grammer LC, Shaughnessy MA, Kenamore BD. Clinical and immunologic outcome of 42 individuals with trimellitic anhydride-induced immunologic lung disease after transfer to low exposure. Allergy Asthma Proc 2000; 21: 355-359.

65 Smith TA, Patton J. Health surveillance in milling, baking and other food manufacturing operations-five years' experience. Occup Med (Lond) 1999; 49: 147-153.

66 Munoz X, Cruz MJ, Orriols R, et al. Occupational asthma due to persulfate salts: diagnosis and follow-up. Chest 2003; 123: 2124-2129.

67 Schunemann HJ, Jaeschke R, Cook DJ, et al. An official ATS statement: grading the quality of evidence and strength of recommendations in ATS guidelines and recommendations. Am J Respir Crit Care Med 2006; 174: 605-614. 